\title{
25 Research Soure \\ Efficient Management Strategy of Malaria Patients in China: A Decision-Tree Modelling Approach
}

\section{Gang Li}

Huazhong University of Science and Technology Tongji Medical College

\section{Donglan Zhang}

University of Georgia

\section{Zhuo Chen}

University of Georgia

\section{Da Feng}

Huazhong University of Science and Technology Tongji Medical College

\section{Xinyan Cai}

University of Georgia

\section{Xiaoyu Chen}

Huazhong University of Science and Technology Tongji Medical College

\section{Shangfeng Tang}

Huazhong University of Science and Technology Tongji Medical College

\section{Zhanchun Feng ( $\square$ zcfeng@hust.edu.cn)}

Huazhong University of Science and Technology

\section{Research Article}

Keywords: Geographic variation; Health seeking behavior; Healthcare institutions; Decision tree

Posted Date: July 20th, 2021

DOI: https://doi.org/10.21203/rs.3.rs-657912/v1

License: (c) (1) This work is licensed under a Creative Commons Attribution 4.0 International License.

Read Full License 


\section{Abstract}

Background: Early accurate diagnosis and risk assessment for malaria are crucial for improving patients' terminal prognosis, and preventing them from progressing to severe or critical state. This study aims to assess the ability of medical institutions at all levels to diagnose malaria and develop a predictive model to guide prevention and reduce diagnostic error.

Methods: A retrospective study was conducted on 494 patients admitted to hospitals with a diagnosis of malaria from January 2014 through December 2016. Descriptive statistics were calculated using Stata 15. Decision tree analysis using the IBM ${ }^{\circledR}$ SPSS ${ }^{\circledR}$ Statistics Version 25 was used to build a model to predict the patients who may be misdiagnosed.

Results: Of the 494 patients included in this study, 136 (27.5\%) patients sought care through a countylevel hospital at their first visit; and 130 (26.3\%), $128(25.9 \%)$, and $41(8.3 \%)$ of the patients went to a prefecture-level hospital, village clinic, and provincial-level hospital, respectively. Nearly $60 \%$ of malaria patients were misdiagnosed on their first visit, and $18.8 \%$ of patients had complications. The median time from onset to the first visit was 2 days (IQR: 0 - 3 days), and the median time from the first visit to diagnosis was 3 days (IQR: 0 - 4 days). The decision tree classification of malaria patients being misdiagnosed consisted of six categorical variables: healthcare facilities for the initial diagnosis, time interval between onset and initial diagnosis, region, residence type, insurance status, and age. Furthermore, the predictive accuracy of the model was $85.0 \%$.

Conclusion: Insufficient diagnostic capacity of healthcare facilities with lower administrative levels for the first visit was found to be the most important risk factors in misdiagnosing patients. Researchers and clinicians should consider strengthening the primary care facilities, time interval between onset and initial diagnosis, administrated residence, and health insurance status to reduce diagnostic errors.

\section{Background}

Malaria is one of the major infectious diseases that continue to present challenges to population health and health systems worldwide, particularly in developing countries.[1,2] Malaria is a leading cause of mortality and morbidity in many developing countries.[1,3] According to the latest data, an estimated 229 million malaria cases and 409,000 deaths occurred globally in 2019.[3] China was once a major malaria-endemic country, but the Chinese government made great strides in preventing and controlling malaria.[4] After 70 years of hard work, there has been no report of autochthonous malaria cases for nearly four consecutive years since $2017,[5,6]$ meeting the goal of malaria elimination set by the World Health Organization.[7, 8]

With the sharp increase in international travel among Chinese people, the risk of imported malaria cases from malaria-endemic areas threatens the maintenance of the malaria elimination goal of China.[9] Among imported malaria, falciparum malaria is the most common plasmodium species, which has the potential for fatality.[10] The fatality rate of malaria in China is rising, with more than four-fifths of deaths 
associated with serious complications, such as severe brain/liver/kidney lesions, shock, and hemolysis. $[11,12]$

It is recommended that all malaria cases be treated effectively and affordably within 24 hours of onset. [13] However, not all patients can get a timely and accurate diagnosis. Most cases of "malaria" (i.e., symptom is fever) are self-diagnosed, and most treatments and deaths occur at home.[14] Early and accurate diagnosis and risk assessment for malaria is crucial for improving patients' terminal prognosis, and preventing them from progressing to the severe or critical state.[15] In addition, it also helps to reduce the direct or indirect treatment costs for patients and the risk of community transmission.[16]

To date, previous studies identified many factors associated with misdiagnosis of malaria, including insufficient diagnostic equipment, means of diagnosis, lack of clinical supervision/training for local clinicians, lack of malaria-related knowledge for travelers, plasmodium species, and health system factors.[17-24] Most of these, however, have been conducted in a few malaria-endemic developing countries, or only in one or a few provinces of China.[17, 25-27] To our knowledge, studies on misdiagnosis of malaria using samples from multiple provinces and rich clinical medical records are limited. This study aims to identify factors associated with the misdiagnosis of malaria and develop a predictive model based on the medical records to guide prevention and reduce misdiagnoses.

\section{Methods}

\section{Study design and site}

A multi-staged systematic sampling approach was adopted to obtain the study population. In each region of China, two provinces with the highest incidence of malaria were selected, including Zhejiang and Jiangsu in Eastern China, Henan and Anhui in Central China, and Yunnan and Sichuan in Western China. In each province, two provincial-level hospitals, five prefecture-level hospitals, ten county-level hospitals with relatively large numbers of malaria cases were selected. We collected all patients' medical records in each selected hospital. Figure 1 shows the geographic distribution of the six selected provinces. Jiangsu and Zhejiang provinces are geographically in proximity to the East China Sea, where the economy is among the best in the country, and have frequent trade exchanges with other countries. Henan and Anhui are China's inland provinces, bordering each other with flat terrain. High-speed rail and highways passing through these two provinces are connected with most other provinces in the country. Sichuan and Yunnan are mountainous regions with relatively lower levels of economic development. Transportation infrastructure and medical facilities in these two provinces are fewer than in the aforementioned provinces.[28]

\section{Data Collection}

This is a retrospective study of 494 patients admitted to hospitals with a diagnosis of malaria from January 2014 through December 2016. These patients were confirmed to be infected by positive Rapid 
Diagnostic Tests (RDTs), microscopy, or Polymerase Chain Reaction (PCR) test. Data were obtained from the patients' medical records using a protocol designed for the study. Demographic, epidemiological, and clinical data were collected from medical records, including age, gender, occupation, education, residence type, health insurance status, detailed course from the onset of symptoms to seeking medical services, treatment details, comorbidities, outcome, as well as blood chemicals and microbiology analyses.

\section{Definitions}

China has five levels of administrative divisions, namely the provincial, prefectural, county, township, and village levels. There are two main types of health facilities in China.[29] One is a professional public health agency, such as Centers for Disease Control and Prevention (CDC), which undertakes the detection of some infectious diseases and the prevention of chronic diseases, as well as the distribution of some free medication, such as antimalarial drugs. The other category is institutions that provide treatment services, including hospitals, township health centers, and village clinics. CDCs and hospitals can be divided into three levels: provincial, prefectural, and county level, aligned with the administrative levels. Township health centers and clinics are generally set up within the jurisdiction of townships and villages. In most cases, medical facilities with higher administrative levels also have higher diagnostic and treatment capabilities.

\section{Statistical Analysis}

The descriptive statistics, Chi-square and t-test analyses were performed with Stata version 15.0 (StataCorp, College Station, TX, USA). Descriptive statistics were used to summarize the sociodemographic characteristics. Statistical significance was defined as a $p$-value $<0.05$. Decision tree analysis using the IBM SPSS Statistics 25 was performed to build an optimum and significant predictive model to predict the probabilities who might be misdiagnosed. The Classification And Regression Trees (CART) techniques were conducted to obtain the best cut-off points in the software.[30,31] We included initial diagnosis (misdiagnosis/correct diagnosis) as a dependent variable and demographic and clinical characteristics variables (age, gender, marital status, occupation, residence type, region, insurance status, plasmodium species, time interval between onset and initial diagnosis, and healthcare facilities for the initial diagnosis) as independent variables in the model. Parameters of the final CART tree model were set as follows: maximum tree depth was five, with minimum cases in parent node as 10 and in child node as 5 .

\section{Ethical approval and consent}

The study was approved by the Ethics Committee of the Tongji Medical College of Huazhong University of Science and Technology (IORG0003571). Written permission to access and analyze the research data was granted by the National Health Commission of the People's Republic of China and the manager of each hospital. Patient information was anonymized and de-identified before analysis.

\section{Results}




\section{Sociodemographic characteristics}

The demographic and clinical characteristics of patients are summarized in Table 1. The median age of the 494 patients was 39 years (range: 11-63 years), and most were male (98.2\%). Of these individuals, around 80 percent were married, 62 percent lived in rural areas, 35 percent were employed in agriculture, and 70 percent had health insurance. The malaria cases were mostly from Plasmodium falciparum: 308 (62.4\%), and cases due to Plasmodium vivax, Plasmodium ovale, and Plasmodium malariae were 95 (19.2\%), $15(3.0 \%)$, and $3(0.6 \%)$, respectively. 
Table 1

Epidemiological characteristics of individuals with imported malaria

\begin{tabular}{|c|c|}
\hline Factors & Number (\%) \\
\hline \multicolumn{2}{|l|}{ Gender $(n=494)$} \\
\hline Male & 485 (98.2\%) \\
\hline Female & $9(1.8 \%)$ \\
\hline \multicolumn{2}{|l|}{ Age (years) $(n=494)$} \\
\hline$<35$ & $205(41.5 \%)$ \\
\hline$\geq 35$ & $289(58.5 \%)$ \\
\hline \multicolumn{2}{|l|}{ Marital Status $(n=494)$} \\
\hline Married & $394(79.8 \%)$ \\
\hline Single/divorce/separated & $100(20.2 \%)$ \\
\hline \multicolumn{2}{|l|}{ Occupation $(n=494)$} \\
\hline Agriculture & $170(34.4 \%)$ \\
\hline No-agriculture & $324(65.6 \%)$ \\
\hline \multicolumn{2}{|l|}{ Residence $(n=494)$} \\
\hline Rural & $304(62.2 \%)$ \\
\hline Urban & $185(37.8 \%)$ \\
\hline \multicolumn{2}{|l|}{ Region $(n=494)$} \\
\hline Eastern & $67(13.6 \%)$ \\
\hline Central & $309(62.6 \%)$ \\
\hline Western & $118(23.9 \%)$ \\
\hline \multicolumn{2}{|c|}{ Plasmodium species $(n=494)$} \\
\hline Unclassified & $68(13.8 \%)$ \\
\hline Plasmodium falciparum & $308(62.4 \%)$ \\
\hline Plasmodium ovale & $15(3.0 \%)$ \\
\hline Plasmodium vivax & $95(19.2 \%)$ \\
\hline Plasmodium malariae & $3(0.6 \%)$ \\
\hline Mixed & $5(1.0 \%)$ \\
\hline
\end{tabular}




\begin{tabular}{|c|c|}
\hline Factors & Number (\%) \\
\hline Village clinic & $128(25.9 \%)$ \\
\hline Township health center & $20(4.1 \%)$ \\
\hline County-level CDC & $22(4.5 \%)$ \\
\hline Prefecture-level CDC & $15(3.0 \%)$ \\
\hline Provincial-level CDC & $2(0.4 \%)$ \\
\hline County-level hospital & $136(27.5 \%)$ \\
\hline Prefecture-level hospital & $130(26.3 \%)$ \\
\hline Provincial-level hospital & $41(8.3 \%)$ \\
\hline \multicolumn{2}{|l|}{ Initial diagnosis $(n=461)$} \\
\hline Misdiagnosis & $265(57.5 \%)$ \\
\hline Correct diagnosis & $196(42.5 \%)$ \\
\hline \multicolumn{2}{|c|}{ Admission pathway $(n=494)$} \\
\hline Emergency & $244(49.4 \%)$ \\
\hline Outpatient & $242(49.0 \%)$ \\
\hline Referral & $8(1.6 \%)$ \\
\hline \multicolumn{2}{|l|}{ Symptom (n = 494) } \\
\hline Fever & $491(99.4 \%)$ \\
\hline Chills & $209(42.3 \%)$ \\
\hline Sweating & $191(38.7 \%)$ \\
\hline Splenomegaly & $7(1.4 \%)$ \\
\hline Anemia & $41(8.3 \%)$ \\
\hline Periodic & $123(24.9 \%)$ \\
\hline \multicolumn{2}{|c|}{ Complications developed $(n=494)$} \\
\hline Yes & $93(18.8 \%)$ \\
\hline No & $401(81.2 \%)$ \\
\hline \multicolumn{2}{|l|}{ Insurance status ( $\mathrm{n}=494)$} \\
\hline Insured & $346(70.0 \%)$ \\
\hline Uninsured & $148(30.0 \%)$ \\
\hline
\end{tabular}




\begin{tabular}{|ll|}
\hline Factors & Number $(\%)$ \\
\hline Hospitalization cost (USD) $(\mathrm{n}=484)$ & $106(21.8 \%)$ \\
\hline $36-500$ & $136(28.0 \%)$ \\
\hline $501-1000$ & $161(33.1 \%)$ \\
\hline $1001-2000$ & $83(17.1 \%)$ \\
\hline $2001-34630$ & Mean, Median, Min, P10, P25, P75, P90, Max \\
\hline Days & $2.0,1,0,0,3,5,20$ \\
\hline Time interval from fever onset to initial diagnosis & $3.5,2,0,0,4,8,90$ \\
\hline Time interval from initial diagnosis to final diagnosis & $5.5,4,1,2,7,10,90$ \\
\hline Time interval from fever onset to final diagnosis & \\
\hline
\end{tabular}

\section{Health seeking behaviour}

One hundred and thirty-six (27.5\%) patients sought medical care through county-level hospitals at the first medical visit; and $130(26.3 \%), 128(25.9 \%)$, and $41(8.3 \%)$ of the patients went to the prefecture-level hospital, village clinic, provincial-level hospitals respectively. Nearly $60 \%$ of malaria patients were misdiagnosed on their first visit, and concerning complications affected $18.8 \%$. Approximately half of the patients were admitted to the hospital via emergency rooms. Patients with fever, chills, and sweating upon admission were 491 (99.4\%), 209 (42.3\%), and 191 (38.7\%), respectively.

Median time intervals were as follows: from onset to the first medical visit, 2 days (IQR: $0-3$ days); from the first medical visit to diagnosis, 3 days (IQR: 0-4 days); and from onset to final diagnosis, 5.5 days (IQR: $2-10$ days). Table 2 showed the time interval from symptom onset to initial diagnosis, and from initial diagnosis to final diagnosis of malaria cases in multiple healthcare institutions. The time interval between onset and initial diagnosis in the provincial-level, prefecture-level, and county-level hospital was 3.3 days, 2.4 days, and 2.2 days, respectively, which was longer than in other health care institutions. The time interval from the initial diagnosis to the final diagnosis in prefecture-level CDC, provincial-level CDC, and county-level CDC was 0.5 days, 1.0 days, and 1.1 days, respectively, followed by provincial-level hospital (1.1 days), and prefecture-level hospital (1.3 days). However, the time interval from the initial diagnosis to the final diagnosis in village clinic, county-level hospital, and township health center was much longer than the aforementioned health care institutions, which was 5.8 days, 4.8 days, and 4.0 days, respectively. 
Table 2

Time interval from symptom onset to initial diagnosis, and from initial diagnosis to final diagnosis of malaria cases in multiple healthcare institutions

\begin{tabular}{|lll|}
\hline $\begin{array}{l}\text { Healthcare } \\
\text { institutions }\end{array}$ & $\begin{array}{l}\text { Time interval between onset and } \\
\text { initial diagnosis } \\
\text { Mean }(95 \% \mathrm{Cl})\end{array}$ & $\begin{array}{l}\text { Time interval from initial diagnosis to } \\
\text { final diagnosis } \\
\text { Mean }(95 \% \mathrm{Cl})\end{array}$ \\
\hline Village clinic & $1.42(0.92-1.91)$ & $5.80(4.42-7.17)$ \\
\hline $\begin{array}{l}\text { Township health } \\
\text { center }\end{array}$ & $1.05(0.28-1.82)$ & $4.00(2.43-5.57)$ \\
\hline County-level CDC & $1.32(0.59-2.05)$ & $1.09(0.11-2.07)$ \\
\hline $\begin{array}{l}\text { Prefecture-level } \\
\text { CDC }\end{array}$ & $1.77(0.85-2.68)$ & $0.47(0.09-0.84)$ \\
\hline $\begin{array}{l}\text { Provincial-level } \\
\text { CDC }\end{array}$ & $1.25(-0.22-2.72)$ & $1.00(-0.96-2.96)$ \\
\hline $\begin{array}{l}\text { County-level } \\
\text { hospital }\end{array}$ & $2.21(1.78-2.63)$ & $4.83(3.28-6.38)$ \\
\hline $\begin{array}{l}\text { Prefecture-level } \\
\text { hospital }\end{array}$ & $2.40(2.00-2.80)$ & $1.29(0.82-1.77)$ \\
\hline $\begin{array}{l}\text { Provincial-level } \\
\text { hospital }\end{array}$ & $3.32(2.09-4.55)$ & $1.12(0.44-1.81)$ \\
\hline
\end{tabular}

\section{Factors influencing initial diagnosis and malaria complications}

Demographic and epidemiological factors influencing initial diagnosis are shown in Table 3. There was a significant difference in misdiagnosis rate for the initial diagnosis between different regions, plasmodium species, and health care facilities. Among patients from Western China, around $67.5 \%$ (79) of patients were not correctly diagnosed, and misdiagnosis rates in Central and Eastern China were $58.8 \%$ (163) and $34.3 \%$ (23) respectively. Among all Mixed malaria cases, 4 cases (80.0\%) were not correctly diagnosed at the first medical visit. The misdiagnosis rates of Unclassified, Plasmodium ovale, Plasmodium falciparum, and Plasmodium vivax were $71.7 \%$ (43), 68.5\% (63), 51.4\% (147), and $46.7 \%$ (7), respectively. Notably, the misdiagnosis rate was up to $100 \%$ at village clinics and township health center, and $68.5 \%$ $(87 / 117)$ in county-level hospital during the initial medical visit. More generally, the rate of misdiagnosis decreased with the improvement of the ranking of health institutions. 
Table 3

Influential factors of the malaria cases at initial diagnosis

\begin{tabular}{|c|c|c|c|}
\hline \multirow[t]{2}{*}{ Influential factors } & \multicolumn{2}{|c|}{ Initial diagnosis (\% or $95 \% \mathrm{Cl}$ ) } & \multirow{2}{*}{$\begin{array}{l}\text { P- } \\
\text { value }\end{array}$} \\
\hline & Misdiagnosis(\%) & $\begin{array}{l}\text { Correct } \\
\text { diagnosis(\%) }\end{array}$ & \\
\hline \multicolumn{4}{|l|}{ Gender } \\
\hline Male & $259(57.3)$ & $193(42.7)$ & 0.574 \\
\hline Female & $6(66.7)$ & $3(33.3)$ & \\
\hline Age (years) & $\begin{array}{l}38.4(37.2- \\
39.5)\end{array}$ & $38.3(37.0-39.6)$ & 0.930 \\
\hline \multicolumn{4}{|l|}{ Marital Status } \\
\hline Married & $217(58.8)$ & $152(41.2)$ & 0.250 \\
\hline Single/divorce/separated & $48(52.2)$ & $44(47.8)$ & \\
\hline \multicolumn{4}{|l|}{ Occupation } \\
\hline Agriculture & $94(59.1)$ & $65(40.9)$ & 0.606 \\
\hline No-agriculture & $171(56.6)$ & $131(43.4)$ & \\
\hline \multicolumn{4}{|l|}{ Residence } \\
\hline Rural & $161(57.1)$ & $121(42.9)$ & 0.841 \\
\hline Unban & $101(58.1)$ & $73(42.0)$ & \\
\hline \multicolumn{4}{|l|}{ Region } \\
\hline Eastern & $23(34.3)$ & $44(65.7)$ & 0.000 \\
\hline Central & $163(58.8)$ & $114(41.2)$ & \\
\hline Western & $79(67.5)$ & $38(32.5)$ & \\
\hline \multicolumn{4}{|l|}{ Insurance status } \\
\hline Insured & $188(58.0)$ & $136(42.0)$ & 0.718 \\
\hline Uninsured & $77(56.2)$ & $60(43.8)$ & \\
\hline \multicolumn{4}{|l|}{ Plasmodium species } \\
\hline Unclassified & 43 (71.7) & $17(28.3)$ & 0.006 \\
\hline Plasmodium falciparum & $147(51.4)$ & 139 (48.6) & \\
\hline Plasmodium ovale & $63(68.5)$ & $29(31.5)$ & \\
\hline Plasmodium vivax & $7(46.7)$ & $8(53.3)$ & \\
\hline
\end{tabular}




\begin{tabular}{|c|c|c|c|}
\hline \multirow[t]{2}{*}{ Influential factors } & \multicolumn{2}{|c|}{ Initial diagnosis (\% or $95 \% \mathrm{Cl}$ ) } & \multirow{2}{*}{$\begin{array}{l}\text { P- } \\
\text { value }\end{array}$} \\
\hline & Misdiagnosis(\%) & $\begin{array}{l}\text { Correct } \\
\text { diagnosis(\%) }\end{array}$ & \\
\hline Plasmodium malariae & $1(33.3)$ & $2(66.7)$ & \\
\hline Mixed & $4(80.0)$ & $1(20.0)$ & \\
\hline \multicolumn{4}{|c|}{ Rank of healthcare facilities for the initial diagnosis } \\
\hline Village clinic & $112(100.0)$ & $0(0.0)$ & 0.000 \\
\hline Township health center & $18(100.0)$ & $0(0.0)$ & \\
\hline County-level CDC & $6(30.0)$ & $14(70.0)$ & \\
\hline Prefecture-level CDC & $6(40.0)$ & $9(60.0)$ & \\
\hline Provincial-level CDC & $1(50.0)$ & $1(50.0)$ & \\
\hline County-level hospital & $87(68.5)$ & $40(31.5)$ & \\
\hline Prefecture-level hospital & $27(21.3)$ & $100(78.7)$ & \\
\hline Provincial-level hospital & $8(20.0)$ & $32(80.0)$ & \\
\hline $\begin{array}{l}\text { Time interval between onset and initial } \\
\text { diagnosis }\end{array}$ & $1.6(1.3-1.9)$ & $2.7(2.3-3.1)$ & 0.000 \\
\hline
\end{tabular}

Most complications affected patients infected with Plasmodium falciparum. Except for prefecture-level hospitals, the incidence of complications was relatively low for patients whose first visit was at a higher administrative level of the health care institution. There were $0 \%, 4.9 \%$, and $8.1 \%$ complications in patients initially visiting provincial-level CDC, provincial-level hospital, and county-level hospital, respectively. In contrast, there were $28.1 \%, 26.9 \%$, and $20.0 \%$ complications in patients initially visiting village clinic, prefecture-level hospital, and township health center, respectively. The proportion of complications in patients with a correct initial diagnosis was $13.3 \%$, whereas, it was $23.3 \%$ in patients with an incorrect initial diagnosis. Furthermore, malaria patients with complications tended to have a significantly longer time interval between onset and initial diagnosis (Table 4). 
Table 4

Influential factors for complications developed among the malaria cases

\begin{tabular}{|c|c|c|c|}
\hline \multirow[t]{2}{*}{ Influential factors } & \multicolumn{2}{|c|}{$\begin{array}{l}\text { Complications developed } \\
\text { (\% or } 95 \% \mathrm{Cl})\end{array}$} & \multirow[t]{2}{*}{$\begin{array}{l}P \\
\text { value }\end{array}$} \\
\hline & Yes & No & \\
\hline \multicolumn{4}{|l|}{ Gender } \\
\hline Male & $91(18.8)$ & 394 (81.2) & 0.793 \\
\hline Female & $2(22.2)$ & $7(77.8)$ & \\
\hline Age (years) & $\begin{array}{l}38.8(36.9- \\
40.8)\end{array}$ & $\begin{array}{l}38.2(37.3- \\
39.2)\end{array}$ & \\
\hline \multicolumn{4}{|l|}{ Marital Status } \\
\hline Married & $71(18.0)$ & $323(82.0)$ & 0.363 \\
\hline Single/divorce/separated & $22(22.0)$ & $78(78.0)$ & \\
\hline \multicolumn{4}{|l|}{ Occupation } \\
\hline Agriculture & $23(13.5)$ & 147 (86.5) & 0.029 \\
\hline No-agriculture & $70(21.6)$ & $254(78.4)$ & \\
\hline \multicolumn{4}{|l|}{ Residence } \\
\hline Unban & $55(18.1)$ & 249 (81.9) & 0.503 \\
\hline Rural & $38(20.5)$ & $147(79.5)$ & \\
\hline \multicolumn{4}{|l|}{ Region } \\
\hline Eastern & 9 (13.4) & $58(86.6)$ & 0.000 \\
\hline Central & $84(27.2)$ & $225(72.8)$ & \\
\hline Western & $0(0.0)$ & $118(100.0)$ & \\
\hline \multicolumn{4}{|l|}{ Insurance status } \\
\hline Insured & 68 (19.7) & $278(80.4)$ & 0.472 \\
\hline Uninsured & $25(16.9)$ & $123(83.1)$ & \\
\hline \multicolumn{4}{|l|}{ Plasmodium species } \\
\hline Unclassified & $24(35.3)$ & $44(64.7)$ & 0.000 \\
\hline Plasmodium falciparum & $61(19.8)$ & $247(80.2)$ & \\
\hline Plasmodium ovale & $6(6.3)$ & 89 (93.7) & \\
\hline
\end{tabular}




\begin{tabular}{|c|c|c|c|}
\hline \multirow[t]{2}{*}{ Influential factors } & \multicolumn{2}{|c|}{$\begin{array}{l}\text { Complications developed } \\
\text { (\% or } 95 \% \mathrm{Cl})\end{array}$} & \multirow[t]{2}{*}{$\begin{array}{l}P \\
\text { value }\end{array}$} \\
\hline & Yes & No & \\
\hline Plasmodium vivax & $2(13.3)$ & $13(86.7)$ & \\
\hline Plasmodium malariae & $0(0.0)$ & $3(100.0)$ & \\
\hline Mixed & $0(0.0)$ & $5(100.0)$ & \\
\hline \multicolumn{4}{|l|}{ Rank of healthcare facilities for the initial diagnosis } \\
\hline Village clinic & $36(28.1)$ & $92(71.9)$ & 0.000 \\
\hline Township health center & $4(20.0)$ & $16(80.0)$ & \\
\hline County-level CDC & $3(13.6)$ & $19(86.4)$ & \\
\hline Prefecture-level CDC & $2(13.3)$ & $13(86.7)$ & \\
\hline Provincial-level CDC & $0(0.0)$ & $2(100.0)$ & \\
\hline County-level hospital & $11(8.1)$ & $125(91.9)$ & \\
\hline Prefecture-level hospital & $35(26.9)$ & $95(73.1)$ & \\
\hline Provincial-level hospital & $2(4.9)$ & $39(95.1)$ & \\
\hline \multicolumn{4}{|l|}{ Initial diagnosis } \\
\hline Misdiagnosis & $61(23.0)$ & $204(77.0)$ & 0.008 \\
\hline Correct diagnosis & $26(13.3)$ & $170(86.7)$ & \\
\hline Time interval between onset and initial diagnosis & $1.4(0.9-2.0)$ & $2.1(1.8-2.4)$ & 0.030 \\
\hline $\begin{array}{l}\text { Time interval between initial diagnosis and final } \\
\text { diagnosis }\end{array}$ & $4.2(3.1-5.4)$ & $3.1(2.5-3.7)$ & 0.080 \\
\hline Time interval between onset and final diagnosis & $5.7(4.5-6.9)$ & $5.3(4.7-6.0)$ & 0.631 \\
\hline
\end{tabular}

\section{Decision tree classifier model}

Figure 2 shows the decision tree classification of malaria patients being misdiagnosed. This model would be useful to identify the risk factors with the introduction of subgroups with similar risk levels and the risk factors for initial misdiagnosis in the studied patients. The decision tree classification of malaria patients being misdiagnosed consisted of six categorical variables that ranked by their importance were the following: rank of healthcare facilities for the initial diagnosis, time interval between onset and initial diagnosis, region, residence type, insurance status, and age. The accuracy of the prediction model was $85.0 \%$. 
The tree showed that in a subgroup of patients who visited clinics and township health centers for the first time, the probability of a patient being misdiagnosed was $100 \%$. In the subgroup of patients who visited county-level hospitals for the first time, with patients from Eastern China, the probability of being misdiagnosed was $30.8 \%$. In the same situation with patients from Central and Western China, if the time interval between onset and initial diagnosis $>0.5$ days, the probability of being misdiagnosed was $68.4 \%$, while if the time interval between onset and initial diagnosis $\leq 0.5$ days and age $>41.5$ years, there was a $100 \%$ probability of being misdiagnosed. In the subgroup of patients who visited healthcare facilities at county-level and above for the first time, the time interval between onset and initial diagnosis $<0.25$ days, and urban residence, $84.6 \%$ of individuals was misdiagnosed. In the same situation with the time interval between onset and initial diagnosis $>0.25$ days, if patients seeking care at different levels of CDC, $32.0 \%$ of individuals were misdiagnosed.

\section{Discussion}

We conducted a retrospective study and created a decision tree to determine the associated risk factors for the patients being misdiagnosed. We found that the level of health care facilities for the initial visit was the most important factor affecting whether malaria patients were correctly diagnosed. The proportion of misdiagnosed patients seeking care in township health centers and clinics was $100 \%$. The proportion of misdiagnosed patients seeking care in county-level hospitals dropped to about $70 \%$. Even for patients seeking care at different levels of CDC in China, the rate of misdiagnosis was still very high, which was far from the goal of the National Malaria Elimination Program (NMEP).[32]

In 2010, the Chinese government launched the NMEP (2010-2020) to enable malaria patients to receive timely treatment and reduce delays. Through this action plan, the government provided a large amount of funding to health facilities at all levels to train clinicians to have the ability to perform blood tests for malaria parasites.[33] The year we studied is at least four years after the comprehensive implementation of the goal of eliminating malaria in 2020 . However, according to our small survey sample, we could see that even if the National Health Commission has developed Rapid Diagnostic Test (RDTs) and introduced it to health institutions at all levels, whether it was a public health agency, such as CDC, or hospitals at the county level or above were not capable of diagnosing malaria. It is a fact that with the elimination of local malaria, clinicians at all levels of health institutions, especially some health institutions at or below the county level, have not been exposed to malaria cases for several years, which can easily lead to clinicians inaccurately diagnosing malaria patients with fever as colds and neglecting to ask about their travel history.[34, 35] Moreover, it was also possible that these institutions may neither have the facilities required for diagnosis nor have physicians qualified to diagnose malaria.[36] In addition, most cases were imported falciparum malaria in the years studied, and the patients were usually in serious condition. $[37,38]$ Clinicians in health institutions at or below the county level may use their experience to make a preliminary malaria diagnosis. However, accurate diagnosis requires microscope tests and PCR. They would recommend patients to a higher-level hospital or CDC for further diagnosis and treatment. 
It is noted that the time interval from the initial diagnosis to final diagnosis for patients seeking care initially in the county-level hospitals, township health centers, and clinics was longer than that of patients seeking care in a higher-level hospital or CDC. If the patient were diagnosed with malaria in time, the clinicians would develop an appropriate treatment plan for the patient, which will significantly reduce the occurrence of complications and prevent the progression of the disease. At the same time, it can also greatly reduce the cost of treatment and the economic burden of patients. The great disparity in the time interval from the initial diagnosis to final diagnosis for patients seeking care between different levels of health facilities should be noted. Patients living near higher-level hospitals usually have access to timely and high-quality medical services compared to patients living in rural areas. In particular, diseases such as malaria are easily misdiagnosed as colds.[39] If primary health institutions cannot make a correct diagnosis for patients from rural areas, it will greatly increase the probability of their condition getting worse. After malaria elimination, it is also necessary to establish a rapid referral system between grassroots medical institutions and higher-level hospitals under the premise of strengthening the knowledge training of clinicians in primary health institutions to understand the possible symptoms of malaria patients.

In our study, we also found that misdiagnosis rates between different regions varied greatly. Patients living in western China were more likely to be misdiagnosed than those living in eastern and western China. It reminds us that the disparity of patients seeking care in different regions should be noted. For rural patients living in western China, due to the inconvenience of transportation, they usually sought care in nearby clinics and township health centers.[25] In the case of insufficient diagnosis and treatment capabilities of local clinicians,[21,40] it was easy to cause patients to be misdiagnosed and delayed. There is a need to allocate more anti-malarial funds to the western region and train qualified doctors to narrow the health disparities between regions.

\section{Limitations Of The Study}

This study has at least three limitations. First, some variables used in the analysis need to be extracted from the medical records. However, a limited number of hospitals surveyed can provide complete medical records. Therefore, patients with incomplete electronic medical records were excluded from this study. Second, some hospitals surveyed refused to provide medical records, so, the actual collected cases are much smaller than the expected cases to be collected.. Third, as to whether the patient was correctly diagnosed, some clinicians may not rely on the gold standard RDTs and microscopic examination but rely on personal experience to diagnose that the patient was infected with the plasmodium parasite and then referred the patient to a higher-level institution for further diagnosis. If, as described above, the clinician was unable to make a definite diagnosis, it was also considered a misdiagnosis. The consequence is that misdiagnosis may be overestimated.

\section{Conclusions}

Insufficient diagnostic capacity of healthcare facilities with lower administrative levels for the initial visit was found to be the most important risk factor in the Diagnosis of malaria patients. This study suggests 
that researchers and clinicians should consider comprehensively healthcare facilities for the initial diagnosis, the time interval between onset and initial diagnosis, residence type, and health insurance status to reduce the misdiagnosis rate.

\section{Abbreviations}

WHO, World Health Organization; NMEP, National Malaria Elimination Program; Rapid Diagnostic Tests (RDTs); CDCs, Centers for Disease Control and Prevention.

\section{Declarations}

\section{Acknowledgements}

We would like to acknowledge the Disease Prevention and Control Bureau, National Health Commission of the People's Republic of China for their strong support of this study. The data collection also was conducted with the help of the various Centers for Disease Control and Prevention in Zhejiang, Jiangsu, Anhui, Henan, Yunnan, and Sichuan. The authors would like to thank all the respondents for data collection and the staff in CDCs and health administrative department for their assistance.

\section{Authors' contributions}

GL, ZCF and DLZ conceived and planed the study, SFT, GL and CYC collected the data, GL, ZC and XYC conducted the data analysis, GL, DLZ and ZC wrote the paper. ZC, SFT, DF, HS, ZHW and YHX commented and revised drafts of the manuscript. All authors read and approved the final manuscript.

\section{Funding}

This study was supported by the National Health Commission of PRC Project "Malaria Elimination Assessment and Malaria Policy Analysis" and the National Natural Science Foundation of China (Grant No. 72074088$)$.

\section{Availability of data and materials}

The datasets used in the current study are available from the corresponding author and will also be presented as an attachment in the article.

\section{Ethics approval and consent to participate}

Ethical approval was obtained from the Ethics Committee of Tongji Medical College,

Huazhong University of Science \& Technology (IORG No: IORG0003571). Permission to access and analyze the research datawas taken from the National Health Commission of People's Republic China and from the manager of each hospital. 


\section{Consent for publication}

Not applicable.

\section{Competing interests}

The authors declare that they have no competing interests.

\section{Author details}

${ }^{1}$ School of Medicine and Health Management, Tongji Medical College, Huazhong University of Science and Technology, Wuhan, Hubei, 430030, China. ${ }^{2}$ Department of Health Policy and Management, College of Public Health, University of Georgia, Athens, GA 30602, USA. ${ }^{3}$ School of Economics, University of Nottingham Ningbo China, Ningbo, Zhejiang, 531200, China. ${ }^{4}$ School of Pharmacy, Tongji Medical College, Huazhong University of Science and Technology, Wuhan, Hubei, 430030, China. ${ }^{5}$ Department of Epidemiology and Biostatistics, University of Georgia, Athens, GA 30602, USA.

\section{References}

1. Weiss DJ, Lucas TCD, Nguyen M, Nandi AK, Bisanzio D, Battle KE, Cameron E, Twohig KA, Pfeffer DA, Rozier JA, et al. Mapping the global prevalence, incidence, and mortality of Plasmodium falciparum, 2000-17: a spatial and temporal modelling study. The Lancet. 2019;394:322-31.

2. Battle KE, Lucas TCD, Nguyen M, Howes RE, Nandi AK, Twohig KA, Pfeffer DA, Cameron E, Rao PC, Casey D, et al. Mapping the global endemicity and clinical burden of Plasmodium vivax, 2000-17: a spatial and temporal modelling study. The Lancet. 2019;394:332-43.

3. World Health Organization. World malaria report 2020. 2021. https://www.who.int/news-room/factsheets/detail/malaria. Accessed Jue 16.

4. Hu T, Liu YB, Zhang SS, Xia ZG, Zhou SS, Yan J, Cao J, Feng ZC. Shrinking the malaria map in China: measuring the progress of the National Malaria Elimination Programme. Infect Dis Poverty. 2016;5:52.

5. Huang Q, Hu L, Liao QB, Xia J, Wang QR, Peng HJ. Spatiotemporal Analysis of the Malaria Epidemic in Mainland China, 2004-2014. Am J Trop Med Hyg. 2017;97:504-13.

6. Zhou S, Li Z, Cotter C, Zheng C, Zhang Q, Li H, Zhou S, Zhou X, Yu H, Yang W. Trends of imported malaria in China 2010-2014: analysis of surveillance data. Malar J. 2016;15:39.

7. Lai S, Sun J, Ruktanonchai NW, Zhou S, Yu J, Routledge I, Wang L, Zheng Y, Tatem AJ, Li Z. Changing epidemiology and challenges of malaria in China towards elimination. Malar J. 2019;18:107.

8. Feng J, Zhang L, Huang F, Yin JH, Tu H, Xia ZG, Zhou SS, Xiao N, Zhou XN. Ready for malaria elimination: zero indigenous case reported in the People's Republic of China. Malar J. 2018;17:315.

9. Li Z, Zhang Q, Zheng C, Zhou S, Sun J, Zhang Z, Geng Q, Zhang H, Wang L, Lai S, et al. Epidemiologic features of overseas imported malaria in the People's Republic of China. Malar J. 2016;15:141. 
10. Zhang SS, Feng J, Zhang L, Ren X, Geoffroy E, Manguin S, Frutos R, Zhou SS. Imported malaria cases in former endemic and non-malaria endemic areas in China: are there differences in case profile and time to response? Infect Dis Poverty. 2019;8:61.

11. Zhang Q, Geng Q, Sun J, Zhang Z, Lai S, Zhou S, Li Z. Epidemiological analysis of the deaths of malaria in China, 2005-2014. Chinese Journal of Preventive Medicine. 2016;50:302-5.

12. Zhang L, Feng J, Zhang S, Xia Z, Zhou S. Malaria situation in the People's Republic of China in 2015. Chinese journal of parasitology parasitic diseases. 2016;34:477-81.

13. World Health Organization. Global technical strategy for malaria 2016-2030. 2021. https://www.who.int/publications/i/item/9789241564991. Accessed Jue 16.

14. Amexo M, Tolhurst R, Barnish G, Bates I. Malaria misdiagnosis: effects on the poor and vulnerable. The Lancet. 2004;364:1896-8.

15. Landier J, Parker DM, Thu AM, Carrara VI, Lwin KM, Bonnington CA, Pukrittayakamee S, Delmas G, Nosten FH. The role of early detection and treatment in malaria elimination. Malar J. 2016;15:1-8.

16. Tang S, Feng D, Wang R, Ghose B, Hu T, Ji L, Wu T, Fu H, Huang Y, Feng Z. Economic burden of malaria inpatients during National Malaria Elimination Programme: estimation of hospitalization cost and its inter-province variation. Malar J. 2017;16:291.

17. Nankabirwa J, Zurovac D, Njogu JN, Rwakimari JB, Counihan H, Snow RW, Tibenderana JK. Malaria misdiagnosis in Uganda - implications for policy change. Malar J. 2009;8:66.

18. Parker DM, Carrara VI, Pukrittayakamee S, McGready R, Nosten FH. Malaria ecology along the Thailand-Myanmar border. Malar J. 2015;14:388.

19. Noor A, Zurovac D, Hay S, Ochola S, Snow R. Defining equity in physical access to clinical services using geographical information systems as part of malaria planning and monitoring in Kenya. Trop Med Int Health. 2003;8:917-26.

20. Sonkong K, Chaiklieng S, Neave P, Suggaravetsiri P. Factors affecting delay in seeking treatment among malaria patients along Thailand-Myanmar border in Tak Province, Thailand. Malar J. 2015;14:1-8.

21. Hänscheid T, Pinto BG, Pereira I, Cristino JM, Valadas E. Avoiding misdiagnosis of malaria: a novel automated method allows specific diagnosis, even in the absence of clinical suspicion. Emerg Infect Dis. 1999;5:836.

22. Allen LK, Hatfield JM, DeVetten G, Ho JC, Manyama M. Reducing malaria misdiagnosis: the importance of correctly interpreting Paracheck $\mathrm{Pf} \circledast$ " faint test bands" in a low transmission area of Tanzania. BMC Infect Dis. 2011;11:1-7.

23. Allen LK, Hatfield JM, Manyama MJ. Reducing microscopy-based malaria misdiagnosis in a lowresource area of Tanzania. Tanzania journal of health research. 2013; 15.

24. Mfuh KO, Achonduh-Atijegbe OA, Bekindaka ON, Esemu LF, Mbakop CD, Gandhi K, Leke RGF, Taylor DW, Nerurkar VR. A comparison of thick-film microscopy, rapid diagnostic test, and polymerase chain reaction for accurate diagnosis of Plasmodium falciparum malaria. Malar J. 2019;18:73. 
25. Wang X-L, Cao J-B, Li D-D, Guo D-X, Zhang C-D, Wang X, Li D-K, Zhao Q-L, Huang X-W, Zhang W-D. Management of imported malaria cases and healthcare institutions in central China, 2012-2017: application of decision tree analysis. Malar J. 2019;18:429.

26. Kain KC, Harrington MA, Tennyson S, Keystone JS. Imported Malaria: Prospective Analysis of Problems in Diagnosis and Management. Clin Infect Dis. 1998;27:142-9.

27. Goldman-Yassen AE, Mony VK, Arguin PM, Daily JP. Higher rates of misdiagnosis in pediatric patients versus adults hospitalized with imported malaria. Pediatr Emerg Care. 2016;32:227.

28. Hartmann R, Wang Ja, Ye T. A comparative geography of China and the US. USA: New York: Springer; 2014.

29. Burns LR, Liu GG. China's healthcare system and reform. 2017.

30. Kroese DP, Botev Z, Taimre T, Vaisman R. Data Science and Machine Learning: Mathematical and Statistical Methods. CRC Press; 2019.

31. De Ville B, Neville P. Decision Trees for Analytics: Using SAS Enterprise Miner. SAS Institute Cary, NC; 2013.

32. National Health Commission of the People's Republic of China. Action plan of China Malaria Elimination (2010-2020). 2010.

http://www.nhc.gov.cn/jkj/s5873/201005/f84f1c4b0f32420990d23b65a88e2d87.shtml. Accessed Jue 16.

33. Feng J, Zhang L, Huang F, Yin J-H, Tu H, Xia Z-G, Zhou S-S, Xiao N. Zhou X-N. Ready for malaria elimination: zero indigenous case reported in the People's Republic of China. Malar J. 2018;17:315.

34. Romay-Barja M, Cano J, Ncogo P, Nseng G, Santana-Morales MA, Valladares B, Riloha M, Benito A. Determinants of delay in malaria care-seeking behaviour for children 15 years and under in Bata district, Equatorial Guinea. Malar J. 2016;15:1-8.

35. Zhang T, Xu X, Jiang J, Yu C, Tian C, Xie Q, Li W. Risk factors of severe imported malaria in Anhui province, China. Acta Trop. 2019;197:104934.

36. Lai S, Li Z, Wardrop NA, Sun J, Head MG, Huang Z, Zhou S, Yu J, Zhang Z, Zhou S-S. Malaria in China, 2011-2015: an observational study. Bull World Health Organ. 2017;95:564.

37. Lin H, Lu L, Tian L, Zhou S, Wu H, Bi Y, Ho SC, Liu Q. Spatial and temporal distribution of falciparum malaria in China. Malar J. 2009;8:1-9.

38. Bi Y, Hu W, Yang H, Zhou X-N, Yu W, Guo Y, Tong S. Spatial patterns of malaria reported deaths in Yunnan Province, China. Am J Trop Med Hyg. 2013;88:526-35.

39. Demissie Y, Ketema T. Complicated malaria symptoms associated with Plasmodium vivax among patients visiting health facilities in Mendi town, Northwest Ethiopia. BMC Infect Dis. 2016;16:1-8.

40. Hänscheid T. Current strategies to avoid misdiagnosis of malaria. Clin Microbiol Infect. 2003;9:497504.

\section{Figures}




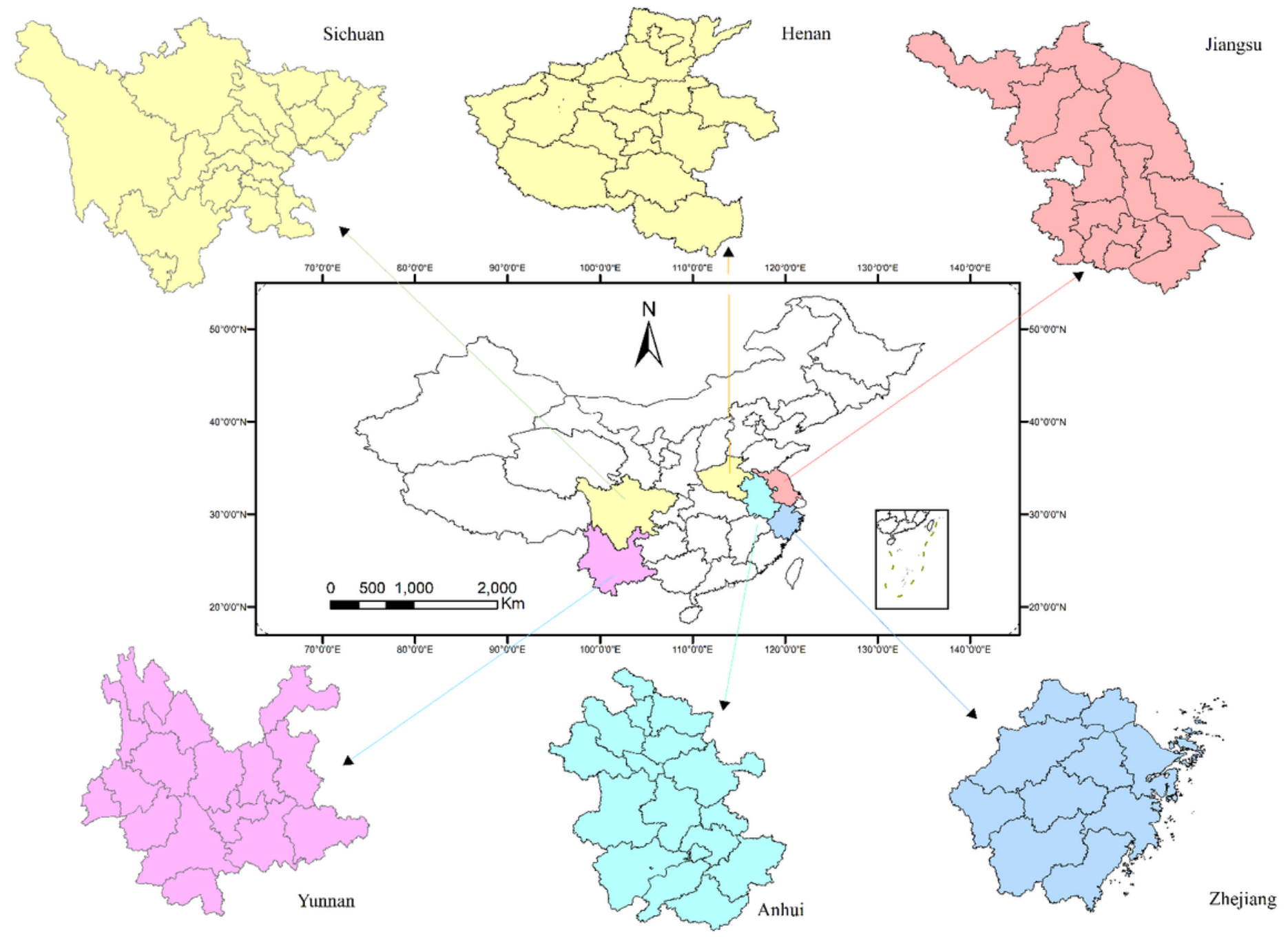

Figure 1

Geographic distribution of the six selected provinces 


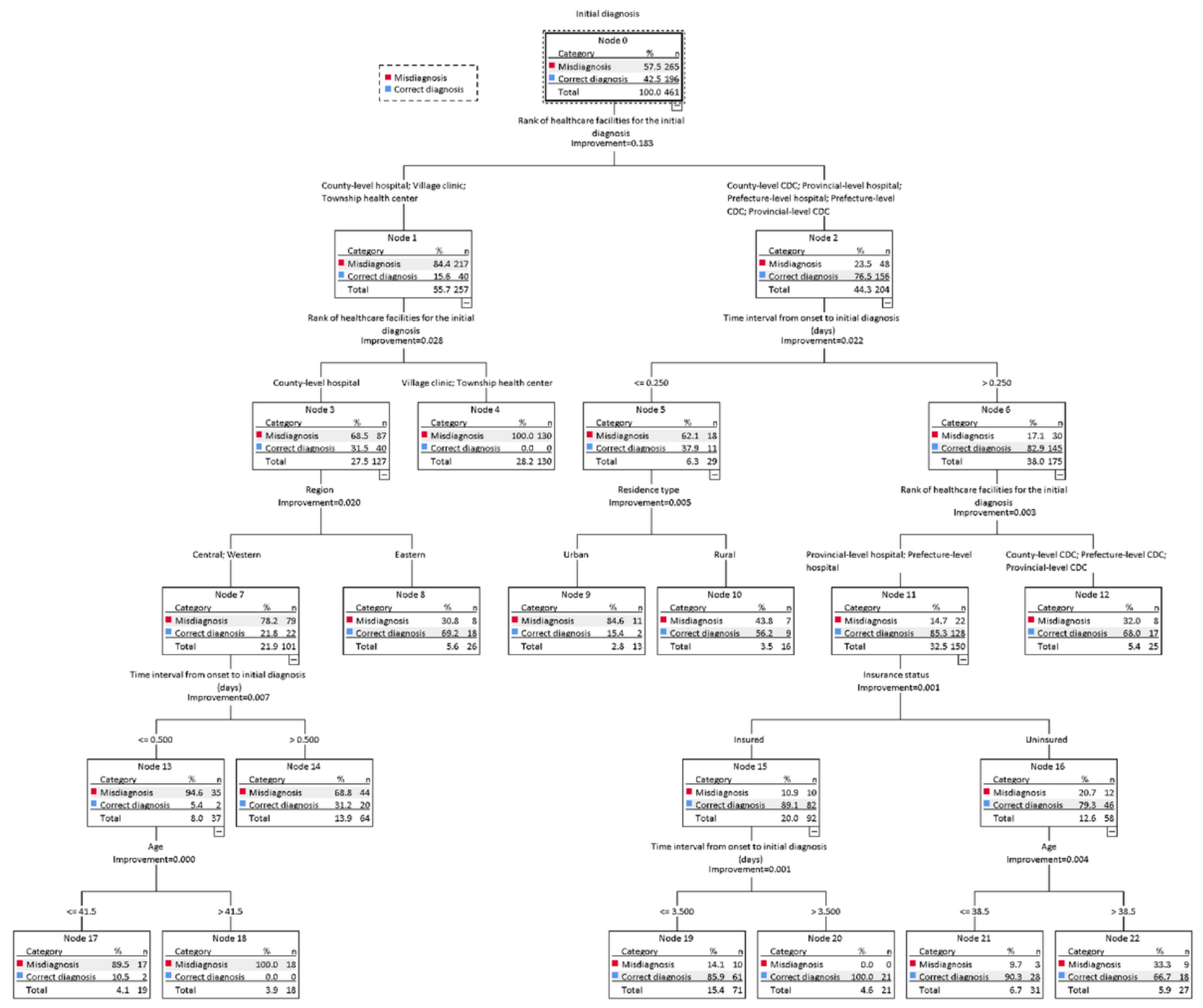

Figure 2

Tree model of initial diagnosis as dependent variable by CART method 